\title{
Author Correction: Human plasma proteomic profiles indicative of cardiorespiratory fitness
}

Jeremy M. Robbins (D), Bennet Peterson (D), Daniela Schranner (D), Usman A. Tahir (D), Theresa Rienmüller (D), Shuliang Deng, Michelle J. Keyes $\mathbb{D}$, Daniel H. Katz (D), Pierre M. Jean Beltran (D), Jacob L. Barber, Christian Baumgartner, Steven A. Carr, Sujoy Ghosh, Changyu Shen, Lori L. Jennings (D), Robert Ross (D), Mark A. Sarzynski (iD), Claude Bouchard (i) and Robert E. Gerszten (iD

Correction to: Nature Metabolism https://doi.org/10.1038/s42255-021-00400-z, published online 27 May 2021.

In the version of this Article originally published, the authors' Competing Interests statement was incomplete. The statement now reads: "S.A.C. is a member of the scientific advisory boards of Kymera, PTM BioLabs and Seer and is a scientific advisor to Pfizer and Biogen. The other authors declare no competing interests."

The error has been corrected in the online version of the Article.

Published online: 27 August 2021

https://doi.org/10.1038/s42255-021-00459-8

(C) The Author(s), under exclusive licence to Springer Nature Limited 2021 